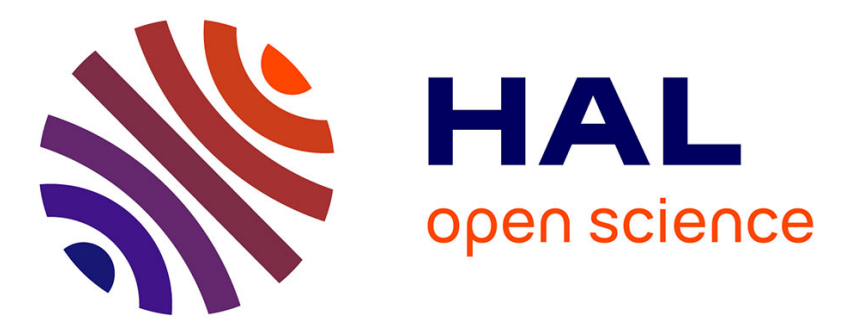

\title{
Uncertainty, vision, and the vitality of the emerging smart grid
}

Aurelie Tricoire

\section{To cite this version:}

Aurelie Tricoire. Uncertainty, vision, and the vitality of the emerging smart grid. Energy Research \& Social Science, 2015, 9, pp.21-34. 10.1016/j.erss.2015.08.028 . hal-02351994

\section{HAL Id: hal-02351994 \\ https://hal-cstb.archives-ouvertes.fr/hal-02351994}

Submitted on 6 Nov 2019

HAL is a multi-disciplinary open access archive for the deposit and dissemination of scientific research documents, whether they are published or not. The documents may come from teaching and research institutions in France or abroad, or from public or private research centers.
L'archive ouverte pluridisciplinaire HAL, est destinée au dépôt et à la diffusion de documents scientifiques de niveau recherche, publiés ou non, émanant des établissements d'enseignement et de recherche français ou étrangers, des laboratoires publics ou privés. 


\title{
Uncertainty, vision, and the vitality of the emerging smart grid
}

\section{Aurélie Tricoire}

Université Paris-Est, Centre Scientifique et Technique du Bâtiment (CSTB), Direction Économie et Sciences Humaines, PST Descartes-Bâtiment "Bienvenüe", 14 Boulevard Isaac Newton, 77420 Champs-sur-Marne, France

E-mail address: aurelie.tricoire@cstb.fr

\begin{abstract}
This paper answers an important question consensually identified as crucial for smart grid roll-out. Our objective is to highlight the reasons for economic, technological and regulatory uncertainty continuing in the smart grid sector. The argument of this paper is that to face uncertainty, actors adopted strategic positioning but not systematically favoring the emergence of a structuring and shared vision of smart grid. However, converging visions are necessary to limit uncertainty and thus secure the sector's development and durability in the coming years.

The results presented here are based on two methodological approaches. First, a social network analysis of worldwide relationships between smart grid actors has been performed to characterize the actors' positioning strategies. The paper identifies four categories of actors: local observers, global observers, experimenters, and central actors. Second, a qualitative analysis of semi-structured interviews with approximately 30 French smart grid stakeholders gave us information on discourses and perceptions of the sector's reality and constraints. It appeared that smart grid merges both long-established actors in the smart grid focal sector, i.e., energy, promoting a highly accurate but strictly energy-oriented perception, and new entrants coming from related sectors such as ICT, offering an open but indistinct perspective. Therefore, stakeholders diverge on the definition and potential source of added value. These results help to elucidate the transition of socio-technical systems. Indeed, at this very moment when contextual uncertainty remains high, it appears that actors from the focal sector play a crucial part in driving the current sector development, whereas new entrants remain unable to modify the sector's regime decisively. One can interpret this situation as a sign of the failure of the smart grid sector to emerge as such. Conversely, one can see here an evolution of focal actors' strategies regarding uncertainty in an innovative socio-technical system in transition. To solve this issue, further studies should be conducted both on the smart grid sector to see how it will evolve and on other sectors to search for similar trends.
\end{abstract}

Keywords: Smart grid, Social network analysis, Strategic positioning, Uncertainty, Socio-technical system transition

\section{Introduction}

This paper answers a crucial issue for smart grid rollout, which is the reasons for continuing uncertainty in the sector. Indeed, uncertainty of various types (e.g., economic, technological, and regulatory) has been clearly identified in recent literature (Section 2) but has not yet been directly investigated. This article proposes to fill this research gap, showing that uncertainty mainly continues because of the inability of smart grid actors to favor the emergence of a structuring and shared vision of the sector. However, structuring and sharing such a vision for smart grid is necessary to limit uncertainty and thus secure the sector's development and durability in the coming years.
Based on insights from sociology and innovation studies, this paper offers an analysis of the smart grid sector conceptualized as a socio-technical system. We rely on an original methodology that combines two approaches for studying actors' cooperation strategies (Section 3). First, a social network analysis exploiting an original database gathering worldwide partnerships in smart grid projects has been performed to characterize actors' positioning strategies at the systemic level. Second, a qualitative analysis of semi-structured interviews with approximately 30 French smart grid stakeholders informed us on the discourses and perceptions on the reality and constraints of the smart grid sector.

This empirical material allows us to investigate the hindrance to the transformative capacity of the 
sector standing at the inter-section of the actors' strategies and the smart grid socio-technical system. On this basis, the paper has two main outcomes (Section 4) that contribute to understanding and explaining how smart grid stakeholders have been reacting and positioning themselves in a complex and uncertain environment. First, we identified four categories of actors regarding their positioning strategies. Second, we demonstrated the importance of the heterogeneous nature of stakeholders to explain the discourse's oscillation between enthusiasm and reluctance regarding the potentialities of smart grid technology.

In the conclusion (Section 5), we argue that in a context of toughened competition and considering the positioning strategies previously highlighted, it appears that stakeholders are unable to build a shared vision, which prevents the smart grid sector from lowering uncertainty, which would allow prospective achievements. We also briefly open a discussion on the possible renewal of actors' strategies involved in innovative socio-technical systems in transition.

\section{Literature review}

Because the recent spreading of awareness that the Earth resources are finite, especially regarding increasing energy scarcity, a dilemma has emerged: how to handle the increase of electricity demand and consumption peaks in a context of energy supply deficit. One possible answer (mostly relevant in Europe) would be to increase energy production through the integration of renewable energies. Another solution (especially in North America) would be to avoid grid malfunctions (mostly during consumption peaks) and the high costs of the associated blackouts, by renewing aging grids. By seeking solutions to the tricky equation of matching electricity supply and demand, it has appeared that smart grid is a possible and realistic option $[41,60]$. Thus, for 10 years, real enthusiasm for smart grid has emerged all around the world-perceptible through the high number of dedicated publications, reports, strategic displays, and R\&D projects-mainly conveyed by related industries, public administrations and politicians, all awaiting economic and environmental profits $[50,63]$.

In this context, smart grid is expected to fulfill a set of specific functions, identified in the literature as being able to solve energy challenges (see among many others [1-4]), such as: (1) the efficient management of supply, including intermittent supply; (2)two-way communication between the producer and user of electricity; (3) the use of information and communication technology(ICT) to respond to and manage demand; and (4) the insurance of safe and secure electricity distribution. Doing so should turn a "dumb" electrical grid into a "smart" one [4, 31].

Considering the high potential of smart grid for solving energy issues, we can legitimately wonder why it has not been massively implemented yet. The literature investigating this issue first notes that no consensual definition of smart grid has emerged yet (for a complete and synthetic review of the literature, see Ref. [40], which propose four types of smart grid definitions reflecting the absence of consensus: (1) "via requirements", (2) "via applied technologies",(3) "via desired applications" and (4) "no clear definition"). It is thus difficult to know precisely what one means when talking about smart grid. The roots of the heterogeneity of smart grid definitions have to be grounded in the geographical, economic and historical specificities of national electrical grids $[4,6]$. Indeed, national specificities (such as national energy mix, industrial policies, polity and corporate governance structure) have long favored the scattering of technological expertise into separate locations. This results in preventing the current homogenization of the smart grid concept $[13,41,50]$. As a result, it appears that smart grid deployment cannot be homogeneous worldwide because it is more likely to depend on the technical characteristics and specific structure of each electrical grid: the more decentralized an electrical grid is, the higher smart grid pervasion will need to be [47].

Thus, considering the lack of a shared definition related to the variety of expected achievements and local constraints, smart grid implementation currently faces major challenges that are considered in literature alternatively as barriers (see Fig. 1 in [2] and [5]) or incentives [18, 34, 54].

The first challenge is to remove uncertainty regarding the cost of smart grid, as many recent reports have noted its increasing deployment costs. Hence, some countries have questioned and even jeopardized smart grid implementation. For instance, despite the European directive on the electricity market [20], Belgium decided not to systematically deploy smart meters (considered the first step of smart grid) because the cost/benefit analysis was not positive. Following the upwards revision of 
smart grid costs, analysts have observed that market uncertainty concerning the smart grid's future evolutions has significantly grown [18, 34, 39], mainly concerning the opportunity to invest in such an uncertain technology $[7,47,60]$.

Indeed, the reassessment of smart grid deployment costs is unanimously related to the literature on technical uncertainty. First, technical uncertainty has an impact on the possible developments of the energy system in its complexity, accentuated by the requirements for integrating intermittent and decentralized power sources [8, 21-23, 34, 51]. Second, technical uncertainty also stems from the lack of (1) technology maturity [46, 61, 62]; (2) necessary technical skills and knowledge [47]; (3) open standards and advanced bidirectional communication systems $[4,18$, $34,39,53]$; and (4) real reflections about cyber security and data privacy issues[36, 39, 46, 60, 63].

When considering the rising costs and technical uncertainty of smart grid, most scholars wonder about the existence of a reliable business model for smart grid deployment when no stabilized technical solution currently exists [14, 22,29, 42, 61, 62]. At present, no clear answer prevails. If cost/benefit analyses have all agreed on a deficit gap between smart grid investment costs and created value; scholars are basically dividing into two categories: those wondering if a business model exists at all and those proposing alternatives to balance the smart grid business model.

In this second perspective, a first option for compensating the demand-response investments and supporting programs is a more accurate valuation of avoided costs thanks to smart grid in electricity generation, transmission, and distribution [3, 33]. To find an equilibrium, some also argue that smart grid assessment ignores or underestimates added value induced by smart grid, for example, in the urban dimension and in city governance [31]. From these perspectives, the smart grid definition border tends to enlarge and thus involves issues, going beyond energy-grid concerns.

A second option to counterbalance the cost-benefit gap consists of focusing on value added for the energy market. For example, this counterbalancing could involve the introduction of dynamic tariffs during peak demand. It would provide economic incentives for end users to adapt their consumption to the energy supply: demand would be compliant with supply. This would require that end users benefit from adapting their consumption. From this perspective, smart grid actors should agree to pay for demand-side management, i.e., to share part of the value with end users. For instance, utility companies and distribution network operator companies could reward end users by offering dynamic tariffs, direct payments or the availability payments for a consumption change at an agreed time, for electricity not consumed, for greenhouse gasses not emitted, or for reducing the energy generation security margin, avoiding the building cost of new generation plants [15]. However, even so, it seems difficult so far to involve end users because the technological and economic aspects of smart grid remain quite complex and thus abstruse: people do not perceive what benefits smart grid could provide in their daily life or from an economical point of view. To overcome this difficulty, more and more smart grid demonstration projects are working with end users who provide feedback on their perception of energy and their behaviors $[25,34]$. First, outcomes have confirmed the theoretical hypothesis of inequity in demand-response management [22], showing, for instance, that peak pricing is perceived negatively and would primarily impact households with limited financial means [48]. Furthermore it appears that feedback devices as they are currently designed have limited influence on household energy consumption [52, 56]. These initial results highlight the challenge for smart grid actors to involve end users through the currently existing demand-response management mechanisms. Furthermore, it reinforces the smart grid actors' appetence for finding alternative valuable options to demonstrate the strength and reliability of smart grid business models.

The third lever of endorsement for smart grid identified in the literature concerns the possible evolution of regulatory measures to build an efficient business model that captures the value of new business models and platforms $[12,30]$. However, considerations about regulation are ambiguous. On the one hand, the lack of a regulatory framework appears as a problem [53] resulting from technical complexity: similar to end users, regulators face difficulty understanding smart grid technical issues, which lowers public awareness and engagement [36, 39]. On the other hand, incentive regulation seems to hinder innovation while not guaran-teeing data security [47]. This suggests that smart grid deployment requires extensive industry-regulator collaboration to structure a regulatory framework adapted to the specificities of smart grid. However, cooperation is difficult: institutional mechanisms are slowly changing and 
technology providers are struggling to adapt their organizational structure to the smart grid market [47]. Nevertheless, public authorities have an important part to play not only regarding regulation but also through the implementation of innovation policies, following the example of the USA [36], China [38], Japan [43] and the EU [50].

This literature review shows that, for a few years, the complex and uncertain environment currently characterizing smart grid has been well known and precisely analyzed. It also shows that scarce explanations were produced to explain why uncertainty does not seem to be decreasing. Hence, this paper proposes to look for reasons underlying the continuing uncertainty in cooperation strategies implemented by smart grid actors. Based on insights from sociology and innovation studies, this paper offers a strategic networking analysis of the smart grid sector that is conceptualized as a socio-technical system $[26,27,44,59]$, which means it includes actors such as firms, research institutes, users or policymakers, institutional structures and specific technologies, all involved in social interactions. To avoid the trend of systemic approaches that focus on meso-level of sectoral transitions $[2,16,17,28]$, this paper relies on an original methodology that allows us to investigate the hindrance to the transformative capacity of the sector standing at the border between the micro-level of actors' strategies and theme so-level of the smart grid socio-technical system. This paper has been inspired both by approaches developed in economic sociology on performativity $[9,10,40]$ and in the social studies on the influence of technologies on expectations, ideas $[5,37,55]$ and networks [45]. Hence, it highlights how crucial it has become to understand and explain how smart grid actors have been reacting and positioning themselves towards systemic uncertainty and how they are influencing the possible socio-technical evolutions of the smart grid sector.

\section{Methods}

This article relies on cross-checking quantitative and qualitative methodological approaches. First, a network analysis allows us to describe the objectivized structure of cooperation in the smart grid ecosystem. Then, a discourse analysis based on data collected through semi-structured interviews with
French smart grid actors makes it possible to qualify and understand the strategic nature of cooperation relationships highlighted by network analysis. The converging results from these two methodological tools thus provide renewed and strengthened insight into smart grid actors 'strategies.

\subsection{Semi-quantitative methodology: social net- work analysis}

Social network analysis studies the structure of relationships (referred to as partnership within the framework of R\&D projects) between social entities (referred to as smart grid actors). This methodological approach characterizes networked structures in terms of nodes and the ties or edges that connect them. Network analysis is a tool processing database-often operated by software-to provide information both on network structure (prioritization, density, etc.) and on nodes' position and relational characteristics (centrality, positioning singularity regarding other nodes, etc.). Furthermore, social network analysis can be usefully enriched by graphic representations illustrating structural results.

The network analysis presented in this paper relies on an original database. At the time this work began in 2011, scarce information was available on smart grid. When searching for data, it appeared that, for example, the Joint Research Center's (JRC)database, listing smart grid projects in Europe, was far from exhaustive, as many French projects were not included. In the same way, data available on Open EI (Open data on Energy Information) and from the US Department of Energy (DoE) on smart grid projects, worldwide and in the US, were incomplete ${ }^{1}$.Furthermore, even if the development of these (partial) lists of smart grid projects was in progress, none of them had gathered data on participants. This means that actors' partnerships were not and still are not analyzed as such.

Because the ambition was to study actors' cooperation strategy through network analysis, we decided to build an original database focused on actors, gathering the list of partners involved in ongoing worldwide projects stamped "smart grid" until May 2013. These projects were first identified in JRC's, Open El's and DoE's databases available in 2012, and then supplemented with 59 non-inventoried projects found via documentary research on the

\footnotetext{
${ }^{1}$ Since then, the updated versions of these databases are much more exhaustive (see, for example, Ref. [30]).
} 
Internet ${ }^{2}$.For each project, we searched for participants' names and geographical locations. Our original database ultimately inventoried 460 projects, but the partner lists had been completed for only 399 projects. To make actors' partnership strategy visible, i.e., to limit actors' dispersal between subsidiaries, we aggregated organizations affiliated with the same entity when it was pertinent. For example, aggregating Edelia with EDF seemed pertinent, whereas RTE and ERDF were listed on their own even if they are also $100 \%$ affiliated to EDF.

\section{Box 1: How to read the network maps?}

Node location

NetDraw's algorithm for node location uses iterative fitting (i.e. starts with a random graph, measures relevance of fit; moves a node, measures relevance; and if it is better, keeps going in that direction...) to locate the points in such a way as to put those with the smallest path lengths as close to one another as possible in the graph. The optional "node repulsion" criterion has been selected. It created separation between objects that would otherwise be located very close to one another. We have also used the optional criterion of seeking to make the paths of "equal edge length" so that the distances between adjacent objects are similar. The result is a graph that preserves many of the features of the dimensional scaling approach (distances are still somewhat interpretable), but where it is usually easier to read - particularly if it matters - specific nodes' location and relational environment (rather than seeing node types of clusters).

Node attributes

A node represents an actor. The data available to characterize a node concern participation in one or several projects, number of partners, relationship intensity, the geographic influence of smart grid projects, and presence in Europe for the world database or in France for the French database. For geographical location, each project has been characterized according to the geographical area where it took place. When a project took place in several countries, aggregated areas were used (see column "Aggregated Areas" in Table 1). Then, actors have been "located" according to the area(s) of the project(s) they were involved in. When an actor was involved in several projects, it was characterized by the aggregated areas used for the projects, to which a "World" category was added for actors involved in at least two different aggregated areas.

Tie-strength

Tie-strength reflects the number of cooperation links between two nodes. The ratio between the weakest tie ( 1 link) and the strongest ( 7 links) is 1-10. Furthermore, an indicator was created to distinguish, among worldwide actors, those involved in Europe.

${ }^{2} 2$ The Internet search induces two main biases: (1) linguistic limitation (we were unable to include projects only referenced in languages other than English, French, Spanish or German); and (2) the perimeter of digital resources (only the data avail-able on
Nodes' colors and shapes correspond to cooperation categories built on the basis of actors' objectified structural positioning resulting from network analysis (see Section 4.1,p. 5).For each graph, node size reflects the node's centrality degree[24], which is defined as the number of link incidents upon a node (i.e., the number of ties that a node has). The degree can be interpreted in terms of the immediate risk of a node catching whatever is flowing through the network (such as a virus, or some information): the bigger a node is, the higher the centrality degree of the actor. In the following graphs, the ratio between nodes with the lowest and the highest centrality degree is $1-5$.

Table 1

Geographical locations.

\begin{tabular}{|c|c|}
\hline $\begin{array}{ll}\text { Aggregated } & \text { area } \\
\text { associated } & \text { with } \\
\text { the actor } & \\
\end{array}$ & Project locations \\
\hline Middle East & $\begin{array}{l}\text { Abu Dhabi, Mediterranean Union, } \\
\text { Lebanon }\end{array}$ \\
\hline Asia & South Korea, Japan, India, Singapore \\
\hline Oceania & Australia, New Zealand \\
\hline North America & USA, Canada \\
\hline Europe & $\begin{array}{l}\text { Germany, Austria, Belgium, Den- } \\
\text { mark, Spain, Finland, Italy, France, } \\
\text { Norway, Baltic Countries, Nordic } \\
\text { Countries, the Netherlands, Swe- } \\
\text { den, Switzerland }\end{array}$ \\
\hline South America & Brazil, Mexico \\
\hline Africa & Senegal \\
\hline World & $\begin{array}{l}\text { At least } 2 \text { aggregated geographical } \\
\text { areas }\end{array}$ \\
\hline
\end{tabular}

Source: <http://faculty.ucr.edu/ hanneman/nettext/C4 netdraw.html\#relations > [consulted 12.04.2014].

Based on this, the article provides a network mapping of the partnership of smart grid actors, first worldwide (399 projects involving 1598 actors), and second, at the French scale (354 actors involved in 70 projects including at least one French organization). The network analysis, performed with Ucinet and NetDraw software programs (see details in Box 1 ), offers a cumulative analysis of cooperation strategies and not an evolution of the actors' partnerships analyzed through a project-based approach (for a project-based approach of smart grid actors, see Ref. [15]). Our network analysis is an actorbased approach, which focuses on partnership intensity over time and throughout projects. For each actor, the graphic representations offer a cumulative view of past and ongoing projects at a specific moment (here, May 2013).

the Internet were reviewed). This excludes, for example, Chinese or Russian projects, which would only be registered in a nonLatin alphabet. 


\subsection{Qualitative data methodology: semi-struc- tured interviews}

From September 2012 to April 2013, a campaign of semi-structured interviews was performed with stakeholders from the French smart grid sector (see Table 2). The qualitative methodology consists of addressing thematic issues, which are pre-identified and listed in an interview grid, but following the conversation's natural flow. During these interviews aimed at investigating the smart grid actors' perception of the sector, the issues discussed dealt with smart grid perimeter and definitions, R\&D project goals, regulation context, impact of political initiatives, identified and expected added values, business models and value distribution, efficiency of demand-response programs and strategic positioning.

27 recorded and transcribed interviews (with 37 persons) were all performed both by a sociologist and an economist. The interviews, lasting on average $1 \mathrm{~h} 30 \mathrm{~min}$ (with an amplitude from $38 \mathrm{~min}$ to 3 h $16 \mathrm{~min}$ ), were thematically analyzed. This means that the two researchers who conducted the interviews first read the transcripts separately to identify salient elements and then confronted their thematic analysis results to build a common data interpretation ensuring the reliability of the study. This reliability was tested by presenting the research results (both qualitative and quantitative) to the interviewed actors during a restitution meeting.

\section{Table 2}

Distribution of people interviewed by organizational category

\begin{tabular}{lc}
\hline Typology of organization & $\begin{array}{c}\text { Number of peo- } \\
\text { ple interviewed }\end{array}$ \\
\hline Aggregator & 2 \\
Consultancy & 1 \\
DSO (Distribution System Operator) & 3 \\
Energy company & 3 \\
Energy lobby & 2 \\
Local public authority & 3 \\
Manufacturer & 5 \\
Public authority & 6 \\
Research institute & 3 \\
Service provider & 5 \\
TSO (transmission system operator) & 1 \\
University & 3 \\
Total & 37
\end{tabular}

\footnotetext{
${ }^{3}$ A star network is characterized by a 100 -centrality degree, whereas a circle network corresponds to 0 .
}

The decision to quote interview transcripts in an anonymous way, without even mentioning organizational affiliation or geographical location, was made because the French smart grid ecosystem at the time was too small and in some regards too singular to avoid any identification. Nonetheless, to ensure that quotations made in the paper are representative of the whole range of interviewed actors, we numbered the transcripts to contextualize the quotations. To address editing length constraints, we only used one quotation source at a time in this paper, but it is noticeable that all the referenced arguments were mentioned by several actors (for detailed results, see Ref. [49]).

\section{Results and analysis}

This section presents the analytical results strengthened by confronting both qualitative and quantitative data.

\subsection{Network analysis}

4.1.1. The network of worldwide cooperation in the smart grid sector

Our worldwide social network highlights the scattering and cooperation weakness of smart grid actors, as illustrated on the cooperation map below (see Graph 1). On this graph, each node represents one of the 1598 actors involved in one or several of the 399 projects listed in our database. It is immediately visible that the network, composed of numerous nodes, is concentric, which is reinforced by its low centrality indicator $(2.6 \%)^{3}$. The principal component (the biggest subnetwork) gathers 1501actors, i.e., $94 \%$ of the worldwide actors in the sector. The other 22components are very small (maximum 10 nodes). Density (number of existing ties compared to the theoretical maximum number of ties) is quite low $(1.8 \%)$, which means that actors are not highly connected to one another. This network, with low centrality and low density but whose principal component gathers $94 \%$ of the nodes, is thus characterized by weak and quite thinly stretched relationships: most of the nodes are weakly related, meaning that the worldwide smart grid sector is not highly integrated regarding cooperation strategies. 


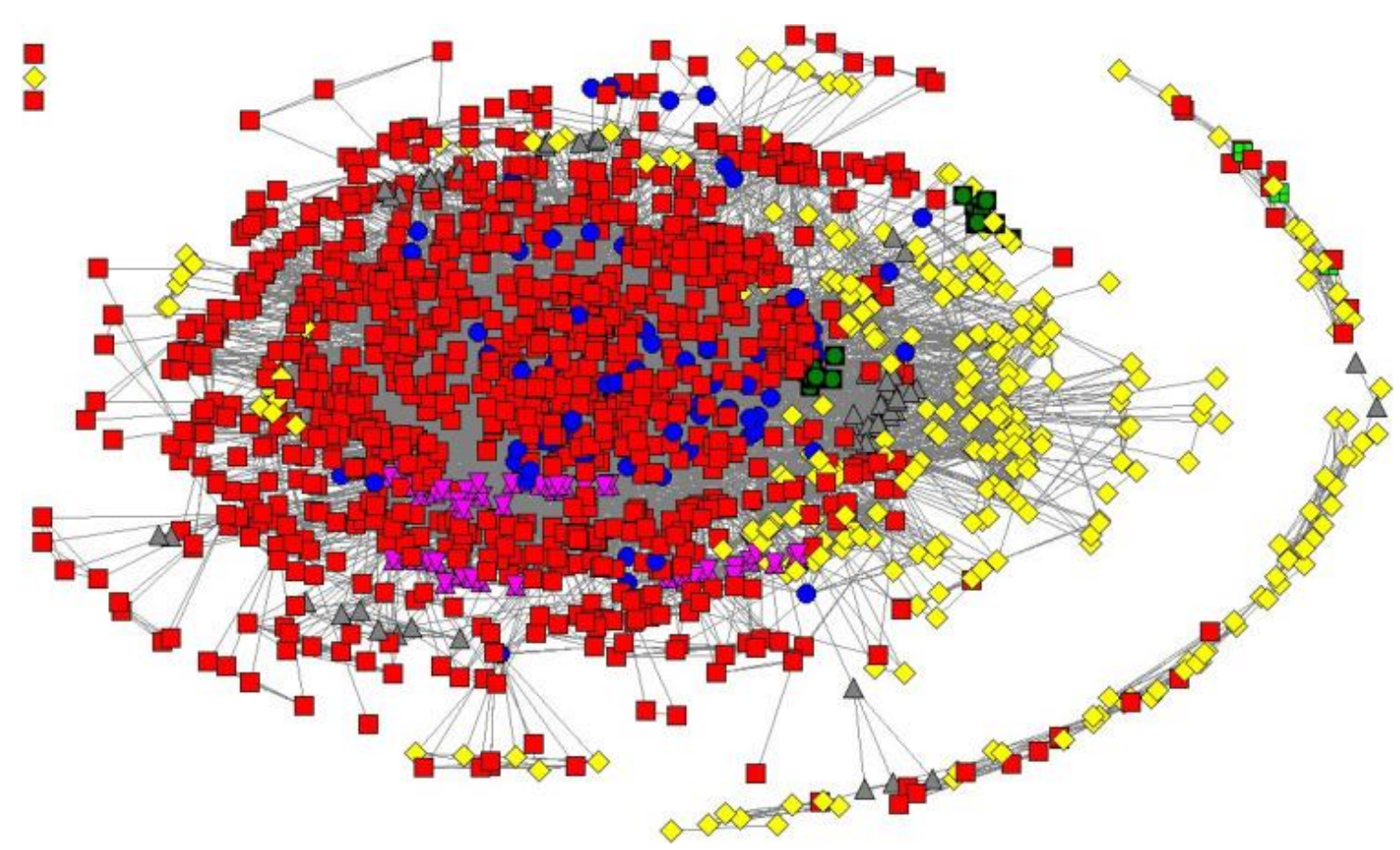

Graph 1. Worldwide partnership in smart grid projects.

Caption: Geographic location of actors' activities.

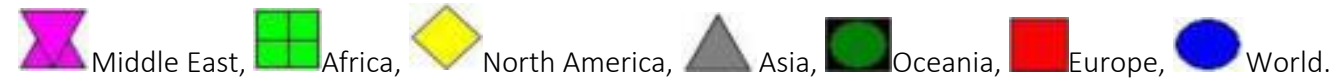

For interpretation of the references to colour in this figure legend, the reader is referred to the web version of this article.

An in-depth analysis of actors' geographical location (nodes' color and shape in Graph 1) reveals the weak presence of African and Oceanian actors. Asian and Middle Eastern actors are much more visible, but nonetheless represent fewer than actors North America and Europe. The latter represent 1082 of the 1598 inventoried actors (approximately 68\%). Even if North America and Europe's predominance for locating smart grid projects could be overestimated (because our database surely underestimates projects data inventoried in non-Latin alphabets), the consolidated Open El database confirms this trend (see http://en.openei.org/ [consulted May 2014]).

Actors involved in projects located in only one geographic area (i.e., 309 actors in North America, 56 in Asia, 49 in the Middle East,16 in Oceania and 3 in Africa) are not very active at the worldwide network scale. In Graph 1, these actors are distributed on peripheral circles, depending on their relationship degree with central actors. Even some actors on outer areas (from North America, Africa and Europe) are no more connected to the main cooperation network. It should be noted that here, activity does not refer to the capacity of projects or actors to produce results, but to activity in cooperation relationships.
Obviously, an actor can have little activity regarding cooperation (having only one partner or a single project) but can be very effective for R\&D results. Cooperation activity only conveys he position in the sector: it is not a quality indicator.

The massive presence of North American and European actors observed on the worldwide smart grid network corroborates actors' discourse on the existence of converging dynamics at work in some areas to strongly promote smart grid development. Indeed, whatever the specific causes for smart grid implementation (aging grids in the USA and the integration of renewable energy in Europe), actors have related them all to the inability of the industry sector, destabilized by the current crisis context, to afford the costs of a deficient energy supply and an increase in energy prices. Obviously, the two areas most concerned by these issues are North America and Europe:

"To revive economy, reliable infrastructures are required as well as cheap energy. These are the keys for a competitive industry. And the [smart grid] objective is precisely to revitalize industry. In the US, the problem is about having a quality and continuous supply. It is very expensive to 
produce if energy is not regularly supplied. For electrosensitive activities, like the paper industry, when a default in the energy supply occurs, you lose your entire production line, which is unaffordable and unacceptable for the industry." ${ }^{4} \# 35$

Politicians have answered this issue by implementing investment policies in grid infrastructures and in economic revival. These policies first took place in the USA (Energy Policy Act 2005, American Recovery and Reinvestment Act 2009):

"With his [investment roadmap in smart grid], he [President Obama] has wanted to revive industry, first for the grid's equipment industry, and then as a consequence for all industrial activities, expecting, of course, job creation. For him, smart grid should be used as a spearhead for revitalizing the national economy, a kind of communication term but based on economic issues." \#26

In addition, Europe-mainly the European Union [50] - has adopted and followed the US strategy to maintain the European industry's competitiveness:

"As in Europe, the crisis also impacted industry. The decision was made to do the same [as the USA]. That is why massive funding has been spent on [smart grid] projects. In the2009-2010 period, research and demonstration projects for smart grid deployment were launched with premarket tests to help European industrialists face the US ones." \#11

It is thus obvious that public authorities have been playing an important part in the smart grid implementation, mainly motivated by the worldwide context of reinforced competition between national industries. This competitive environment between Europe and North America has been identified as crucial in the actors' discourses, which is clearly visible in Graph 1, considering the nodes' separated distribution.

\subsubsection{Network typology of actors: observers and/or experimenters}

An in-depth network statistical analysis of our database highlights the importance of taking into account for each actor, on the one hand, the number

\footnotetext{
${ }^{4}$ Indented text blocks are quotations from semi-structured interviews with French smart grid actors. The reference numbers are
}

of partnerships and, on the other hand, the relationship intensity.

Concerning the number of partnerships, network analysis allowed us to identify the most connected actors of the network (between 31 and 573 partners), visible in the center of Graph 1 . In comparison, 31 is the average number of partners in the overall sample and accounts for $75 \%$ of actors above, which allows us to say that they are very active in the network. These actors are all involved in worldwide or European cooperation projects.

Considering relationship intensity, it appears that cooperation is also dependent on relationship permanence, visible in the links intensity. That is why we characterized each actor with the indicator of centrality degree, integrating both number of partners and links intensity (see section Node attributes).

Using these network indicators to sort the actors, a typology emerged distinguishing four distinct groups. Then, to characterize the actors from each network analysis category, we had to develop a better quantitative definition of the various partnerships. In this case, partnership had two components: the number and the size of the projects in which an actor is involved. The hypothesis is that cooperating with many partners in a few large projects reveals a different relationship and thus a different positioning strategy than having many partners participating in many large projects.

A quartile analysis showed that $75 \%$ of actors were involved in between 1 and 2 projects and the remaining $25 \%$ participated in more than 2 projects (up to 43). In this context, being involved in more than 2 projects is considered having many projects. To distinguish actors involved in large projects from those involved in small projects, we first calculated an average project size for each actor (i.e., for each actor, the total number of partners was divided by the total number of projects). Then, based on a quartile analysis, we identified markers to delimit categories in terms of the size of an average project, the result being that actors are involved in small projects when their average project size is between 1 and 7partners, in medium projects when the size is between 8 and 12, in large projects when it is between 13 and 21, and in huge projects when it is between 22 and 90.

used to distinguish the source of the quotations used in the paper. 
We then compared the four categories of actors obtained with network analysis using these elements of characterization (see Table 3) to better

\section{Table 3}

Categories of actors in worldwide network typology.

\begin{tabular}{|c|c|c|c|c|}
\hline Network typology (\%) & $\begin{array}{l}\text { Average number of } \\
\text { projects }\end{array}$ & $\begin{array}{l}\text { Corresponding cate- } \\
\text { gory of projects num- } \\
\text { ber }\end{array}$ & $\begin{array}{l}\text { Average number of } \\
\text { partners }\end{array}$ & $\begin{array}{l}\text { Corresponding cate- } \\
\text { gory of average pro- } \\
\text { ject size }\end{array}$ \\
\hline $\begin{array}{ll}\text { Local } & \text { observers } \\
(48.2 \%) & \end{array}$ & 1.2 & Few projects $(<2)$ & 7 & $\begin{array}{l}\text { Small (between } 1 \text { and } \\
\text { 7) }\end{array}$ \\
\hline $\begin{array}{l}\text { Global } \\
(44.1 \%)\end{array}$ & 1.5 & Few projects $(<2)$ & 46 & Huge (above 22) \\
\hline Experimenters (6.3\%) & 5.6 & Many projects $(>2)$ & 11.7 & $\begin{array}{l}\text { Medium (between } 8 \\
\text { and } 13 \text { ) }\end{array}$ \\
\hline Central actors (1.4\%) & 17.8 & Many projects (>2) & 12.7 & $\begin{array}{l}\text { Medium (between } 8 \\
\text { and } 13 \text { ) }\end{array}$ \\
\hline
\end{tabular}

understand the actors' positioning strategy and to characterize them.
Local observers (771 actors, 48.2\%) are involved in a few projects (between 1 and 3, on average 1.2), quite small (from 1 to 12 partners, on average 7) and located in a single geographical area. 64.7\%are Europeans, 28.2\% North Americans, 3\% Asians, 1\% Oceanians, and $0.4 \%$ Africans. Only $2.7 \%$ are worldwide actors. Thus, local observers are mainly national actors, initiating their positioning on the smart grid sector by getting involved in a few practical projects with local partners.

Global observers (704 actors, 44.1\%) are quite central in the worldwide network because they participate in huge projects (22 partners and more, on average 46). However, the number of projects they are involved in remains small (on average 1.5). Consequently, these actors have a cooperation network of low intensity, even if they have a dense network of partnerships, focused on a single geographical area. $70.7 \%$ are Europeans, $11.9 \%$ North Americans, $7 \%$ from the Middle East, $4.7 \%$ Asians, and 1.1\% Oceanians. None are Africans, and only $4.5 \%$ are worldwide actors. Global observers are mainly continental actors, whose core activities are connected to the smart grid sector. They are interested in the smart grid sector to eventually initiate their positioning strategy.

Experimenters (101 actors, 6.3\%) are involved in many projects (between 4 and 10, on average 5.6) of medium size (on average 11.7partners). This suggests that these are applied projects. Most are Europeans $(75.2 \%), 16.8 \%$ are worldwide, and $7.9 \%$ are North Americans. Experimenters are narrowly related to the sector of energy and smart grid, multiplying participation in applied projects.

Finally, central actors ${ }^{5}$ (22 actors, $1.4 \%$, listed in Table 3 ) are characterized by a large amount of projects (between 11 and43 projects, on average 17.8), whereas the size of those projects remains medium (12.7 partners per project). In addition, the difference in size between the various projects is rather important (from 3 to 90 partners). 13 are worldwide actors (59.1\%), and 9 are active only in Europe (40.9\%). The central actors combine the strategies of both experimenters and observers because they are simultaneously involved both in quite small and applied projects with well-identified partners and in large-scaled worldwide projects, allowing them to monitor R\&D trends within the smart grid sector. Hence, these actors are central in the worldwide network, as they have numerous partners as well as close cooperation relationships.

In Graph 2, which relies on the same data as Graph 1 but focuses on partnerships with more than 3 cooperation links, we applied the network typology (see caption), which improves the understanding of actors' positioning and thus highlights the smart grid sector's functioning. Indeed, the choice to reduce the worldwide network to partnerships with more than 3 cooperation links highly simplifies the graph.

\footnotetext{
${ }^{5}$ We use the "central actors" term that is richer than "nodal actors" because these actors are both central and nodal. The centrality in network analysis (see Box 1) measures the impact of each actor on the network overall activity, taking into account
}

relationship intensity. The nodality measures the intermediary position of key actors. Central actors are gathering both characteristics. 


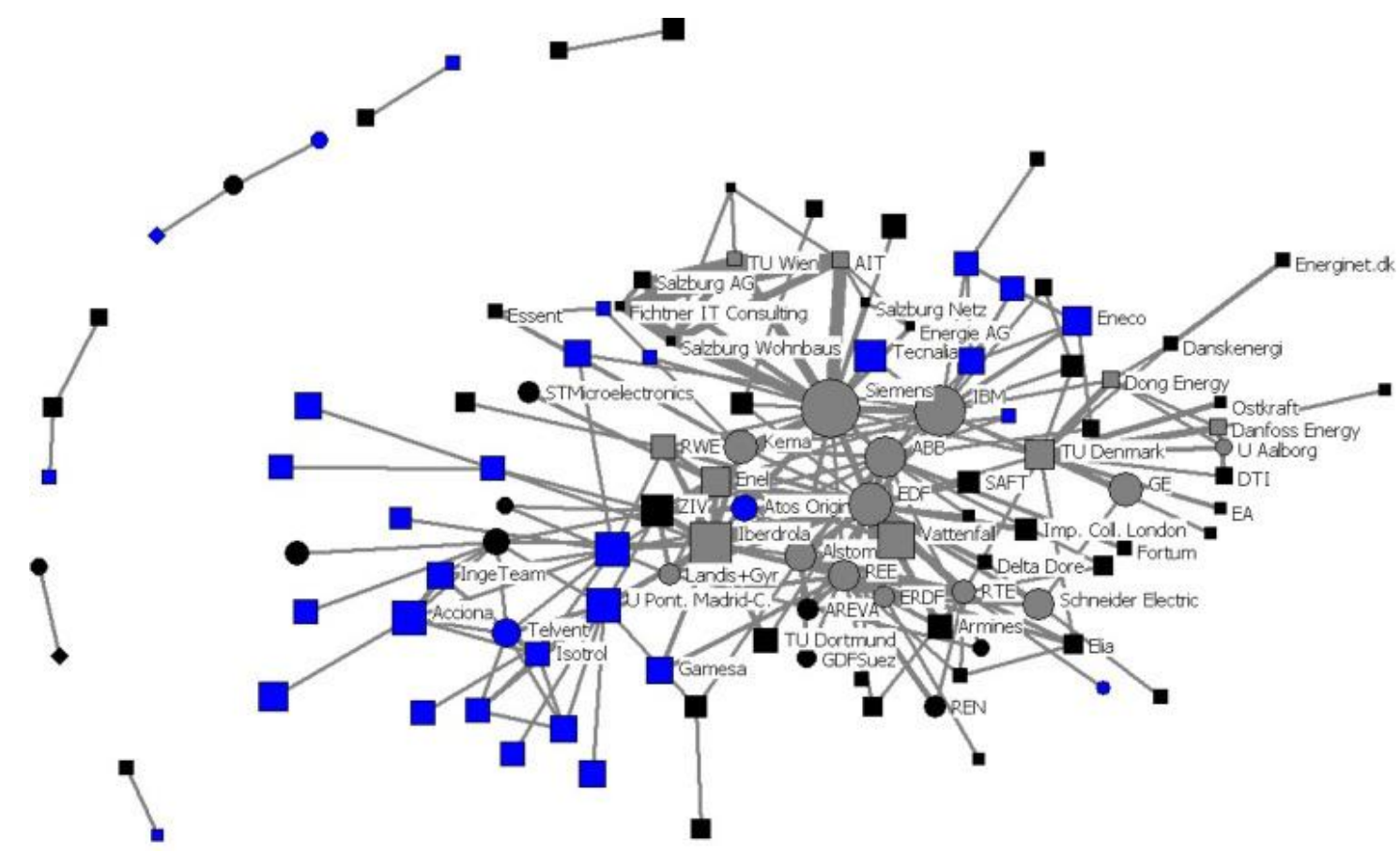

Graph 2. Network typology applied to worldwide intense partnership.

Caption: Geographical scales (shapes): $\bigcirc$ World $\square$ Europe.

Network typology (colors): $\square$ Experimenters/ Local observers/ $\square$ Global observers $\square$ Central actors

Note 1: Only partnerships with more than 3 cooperation links are represented here. The actor's name is available for those with 4 cooperation links or more. (For interpretation of the references to colour in this figure legend, the reader is referred to the web version of this article.)

Note 2: TU stands for "Technological University" and U for "University".

Note 3: For interpretation of the references to colour in this figure legend, the reader is referred to the web version of this article.

Indeed, it excludes the local observers from the graphic representation, which is coherent with the category definition, i.e., actors involved in very few (less than 2 projects) projects. This new version of the worldwide smart grid network clearly illustrates how central actors are both related to experimenters and to global observers as they are involved both in local projects and in huge projects aiming at monitoring the smart grid technological trends. It validates that the network typology based on the statistical analysis of our database is coherent with the reality of network organization. Moreover, it is visible that central actors are not necessarily the nodes with the biggest centrality degree (seeable in node size). Finally, one can observe some proximity between the more active global observers, for example in the top righthand corner or in the bottom left-hand corner. It is explained by their belonging to few huge projects.

In Table 4, the 22 central actors from our network typology are indexed according to the actors' typology commonly used in literature (mostly based on the analysis of the European area, see Ref. [4, 13, 48]). These actors' typologies usually propose three categories: (1) energy utility suppliers (i.e., energy suppliers and operators on transmission and distribution systems), (2) smart grid technology suppliers (i.e., suppliers of infrastructure for energy transmission and distribution, metering equipment suppliers and ICT firms), and (3) research institutes (i.e., universities and research centers).

The 22 actors identified as central in cooperation network belong to one of these 3 categories: no new type of actor has emerged from network analysis. What network analysis has added to the actors' typology is that, at the moment of our study, first, most of the central actors (excepting research institutes) belong to the energy sector, and second, ICT firms belong to the local or global observers categories and, consequently, are not dominant at the worldwide scale, whereas they are quite numerous to be involved in the sector. Indeed, only one, IBM, is identified as a worldwide central actor for the smart grid sector.

The network typology also matches with qualitative data. Indeed, the French actors' discourse also states that smart grid currently is mostly structured by electrical grids, even if some pilot sites are also 
experimenting with gas and water. As electricity is a non-storable utility, the issue of closely adjusting demand to supply to avoid losses is recurrent because electrical grids exist:

"What I can say is that smart grids, in electrical grids, are not new. In fact, it is more a natural evolution of technology applied to electrical grids. Electrical grids have always been "smart", from their very beginning. Indeed, the original idea to count with meters, whereas first, people were paying a flat fee... it was quite a start for smart grid. If smart grid is now at stake, it is because current technological progress allows us to implement ideas that were already in mind 20 or even 30 years ago. [...] The idea to use meters as grid sensors and to use meters to manage the withdrawal of end users' demand withdrawal has existed for ages." \#37

Table 4

Categorization of the 22 worldwide central actors.

\begin{tabular}{ll}
\hline Actors & $\begin{array}{l}\text { Typology of organization (literature catego- } \\
\text { rization) }\end{array}$ \\
\hline ABB & Supplier of transmission and distribution in- \\
& frastructure (2) \\
AIT & University/research center (3) \\
Alstom & Supplier of transmission and distribution in- \\
& frastructure (2) \\
Danfoss energy & Supplier of transmission and distribution in- \\
& frastructure (2) \\
Dong energy & Energy supplier (1) \\
EDF & Energy supplier (1) \\
Enel & Energy supplier (1) \\
ERDF & Distribution system operator (1) \\
General electric & Supplier of transmission and distribution in- \\
& frastructure (2) \\
Iberdrola & Energy supplier (1) \\
IBM & ICT (2) \\
Kema & Consultant specializing in energy (3) \\
Landis + Gyr & Metering equipment supplier (2) \\
REE & Transmission system operator (1) \\
RTE & Transmission system operator (1) \\
RWE & Energy supplier (1) \\
Schneider electric & Supplier of transmission and distribution in- \\
Siemens & frastructure (2) \\
TU Denmark & Supplier of transmission and distribution in- \\
TU Wien & frastructure (2) \\
U Aalborg & University/research center (3) \\
Vattenfall & University/research center (3) \\
Note: TU stands for "Technological University" and U for "Univer- \\
sity". & Energy supplier (1) \\
&
\end{tabular}

${ }^{6}$ Austrian Climate \& Energy Fund: Hit with 6 partners, Smart Web Grid with 6partners, V2G Strategies with 6 partners, V2G Interfaces with 6 partners, Consumer to Grid (C2G) with 5 partners, DG Demonet Smart Low Voltage Grid with 6 partners, DG Demonet Validierung with 6 partners, Smart Synergy with 6 partners and B2Gwith 4 partners.
The specificity of electricity and thus of electrical grids is probably the main reason for enthusiastically adopting smart grid in this sector first. Network analysis also shows secondary networks, which gather partners (only central actors and experimenters) who are especially used to working together, visible on Graph 2. One of the most important networks involves AIT and TU Wien, having 12and 9 cooperation links with Siemens, respectively, both having 8 with Salzburg Wohnbaus, and having 11 with one another. Thus a strong secondary network has emerged (as each actor has a rather high connectivity degree altogether, which means that each actor is connected to several partners belonging to this particular secondary network) between 6 actors (Siemens, Salzburg Wohnbaus, Fichtner It Consulting, TU Wien, Salzburg AG and AIT) structured by 9 projects ${ }^{6}$ with 5.6 partners on average, all cofunded as part of the Austrian Climate \& Energy Fund. Another example is the secondary network between EDF, Alstom, RTE, ERDF, Armines and Schneider Electric mainly structured by $12^{7}$ projects co-funded by the EU, ADEME (French Agency for Environment and Energy Control) and the Mediterranean solar plan of the Union for the Mediterranean (MSP-UfM). These projects include 15 partners on average. This first analysis highlights a type of backbone for cooperation by making the most robust and structuring relationships for the worldwide smart grid sector visible. It also shows that projects' superposition designates some key funders with strong impacts on sector evolutions. This confirms previous results according to which public administrations and politicians have been playing a key role in smart grid development, mainly through $R \& D$ programs and innovation policies [36, 38, 43, 50].

\subsubsection{Smart grid development in France}

In this section, our French database (with 354 actors involved in 70 French projects or having a French pilot site) is exploited using the network typology built at the worldwide scale. It allows us to study the specificities of French actors' relationships and their impact on the smart grid sector (see Graph 3). It is clear that the French cooperation network is slightly different from the worldwide cooperation network, as its centrality degree is lower (9.1\%), with sub-networks

\footnotetext{
${ }^{7}$ European Union: Grid4EU with 25 partners, Twenties with 26 partners, SmartLife with 8 partners and Safewind with 21 partners; ADEME: Smart Electric Lyon with 18 partners, Venteea with 10 partners, Nice Grid with 13 partners, Postes Intelligents with 3 partners, Smart Grid Vendée with 8 partners, and Premio with 15partners; MSP-UfM: MedGrid with 21 partners and TransGreen with 13 partners.
} 
less dependent on actors located at the center (i.e., having the largest number of partners). The main component of the French network gathers 342 actors (i.e., $96.6 \%$ of the network), whereas the other 4 components gather only 4 nodes each. Network density is comparable to the worldwide network: $24 \%$ (i.e.,86 of 354 actors) have 2 links or more, whereas we have $28 \%$ for the worldwide scale.

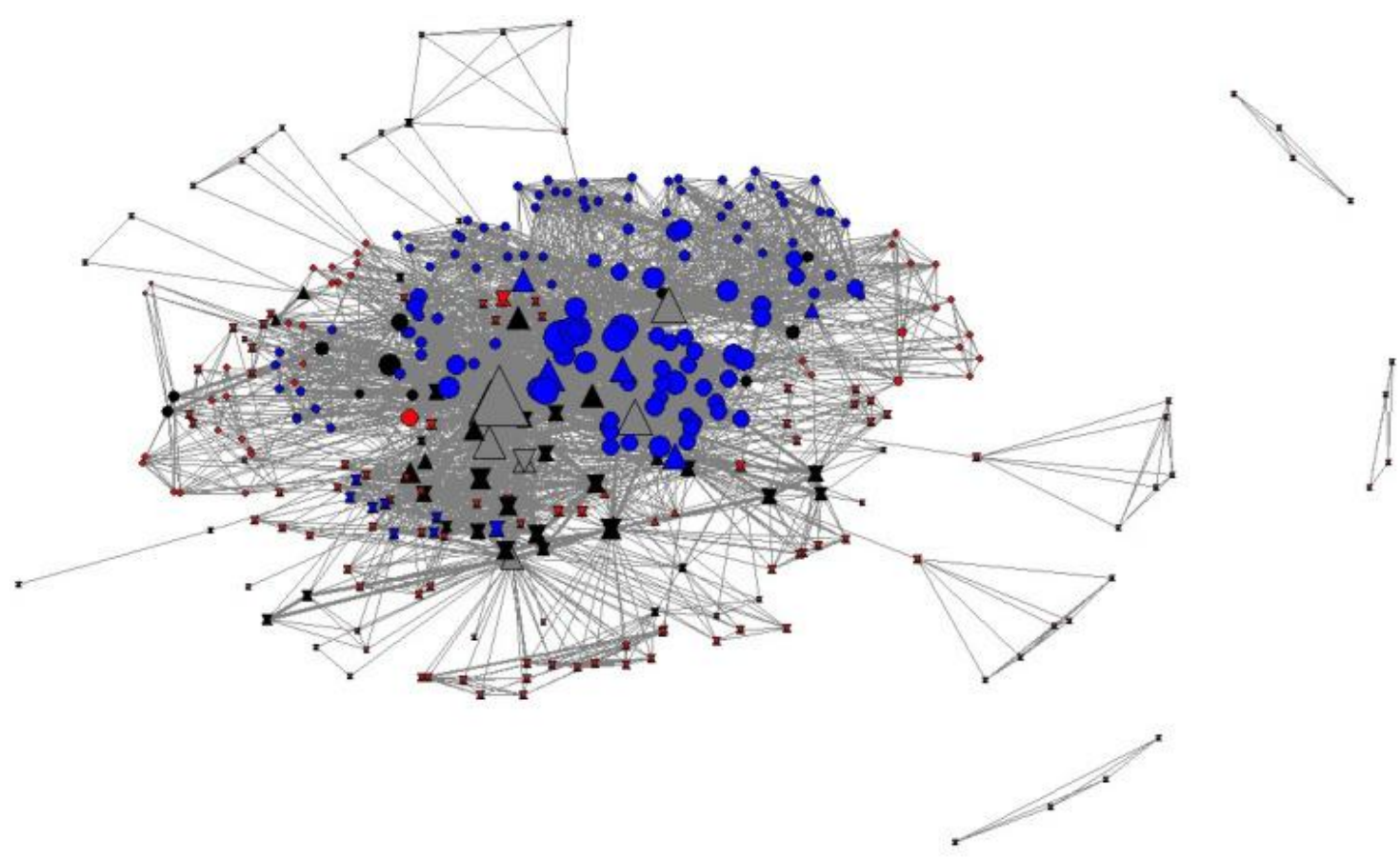

Graph 3. Network typology of French partnerships.

Caption: Geographical scales (shapes): $\triangle_{\text {France }} \triangle$ France \& Europe/ $\bigcirc$ Europe.

Network typology (colors): $\square$ Experimenters/ Local observers $\square$ Global observers $\square$ Central actor.

Note 1: The "France" scale concerns actors involved in projects only deployed in France, whereas the "France \& Europe"scale characterizes actors involved in French and European projects (with pilot sites in another European country).

Note 2: For interpretation of the references to colour in this figure legend, the reader is referred to the web version of this article.

To adapt the network typology to the smaller scale of the French sector (lower number of projects and partners), we marginally modified the statistical characteristics of each category of actors(see Table 5): here, having many projects means having more than 1 project and the thresholds in terms of project size are $1,8,12,21$ and 42 partners (previously 1, 7, 12, 21 and 90). However, despite these marginal modifications, it appears that the network typology remains pertinent and operational at the French scale.

Table 5

French actors' categories of network typology.

\begin{tabular}{|c|c|c|c|}
\hline Typology & $\begin{array}{l}\text { Analytical scale (\% of the } \\
\text { sample) }\end{array}$ & $\begin{array}{l}\text { Average number of projects } \\
\text { and corresponding category } \\
\text { of project number }\end{array}$ & $\begin{array}{l}\text { Average number of partners } \\
\text { and corresponding project } \\
\text { size }\end{array}$ \\
\hline \multirow[t]{3}{*}{ Local observers } & World (48.2\%) & 1.2 & 7 \\
\hline & France (46.9\%) & 1 & 8.6 \\
\hline & & Few & Small \\
\hline \multirow[t]{3}{*}{ Global observers } & World (44.1\%) & 1.5 & 46 \\
\hline & France $(38.1 \%)$ & 1.4 & 24.9 \\
\hline & & Few & Huge \\
\hline \multirow[t]{3}{*}{ Experimenters } & World (6.3\%) & 5.6 & 11.7 \\
\hline & France $(12.7 \%)$ & 2.8 & 9.9 \\
\hline & & A lot & Medium \\
\hline \multirow[t]{3}{*}{ Central actors } & World (1.4\%) & 17.8 & 12.7 \\
\hline & France (1.3\%) & 10.4 & 11.8 \\
\hline & & A lot & Medium \\
\hline
\end{tabular}


An in-depth analysis of Table 5 shows that experimenters in France are significantly more numerous than at the worldwide scale, even if they are involved in fewer projects. This indicates that applied projects are flourishing in France, probably as a result of public programs implemented with ADEME's specific funds.

Comparing French and worldwide databases (Graph 2, Graph 4) shows that some worldwide central actors simply disappeared at the French scale, such as General Electric, TU Denmark, Kema, TU Wien, U Aalborg, Atos Origin, Danfoss Energy and Dong Energy. Other worldwide central actors became global observers (Siemens, Iberdrola, Vattenfall, REE, RWE and Enel) or experimenters (IBM and Landis + Gyr) at the French scale. Only EDF, ERDF, RTE, Schneider Electric and Alstom remained central both worldwide and at the French scale. On the contrary, some actors have extended the scope of their activities: Armines, CEA and GDF-Suez are central actors within the French smart grid sector, whereas they are experimenters at the worldwide scale.

The French cooperation network is obviously structured around a backbone of secondary networks visible on Graph 4, as observed at the worldwide scale. Indeed, EDF and Armines cooperated 7 times. EDF worked 6 times with ERDF, 5 times with Schneider Electric, Eneland Delta Dore, and 3 times with Alstom. ERDF became involved in 5 projects with Armines and RTE, 4 with Alstom and 3 with Schneider Electric. These cooperation relationships are organized approximately 12 projects, and ${ }^{8}$ (each involving at least 3 of these actors) were co-funded by the EU, ADEME, Oséo (French Agency for Innovation) and the Single Interdepartmental Fund (Fonds Unique Interministériel, or FUI).

Among the French central actors, EDF occupies a singular and dominant position, as it is the historical French energy producer. However, although it is the most active actor in the French smart grid sector (gathering both the most numerous and most intense cooperation relationships), it is not central (according to the network analysis definition, i.e., it does not prevent relationships between other actors) because cooperation exists apart from EDF's involvement. Indeed, EDF is not involved in 7 projects co-funded by ADEME and ANR (French Agency for Research).
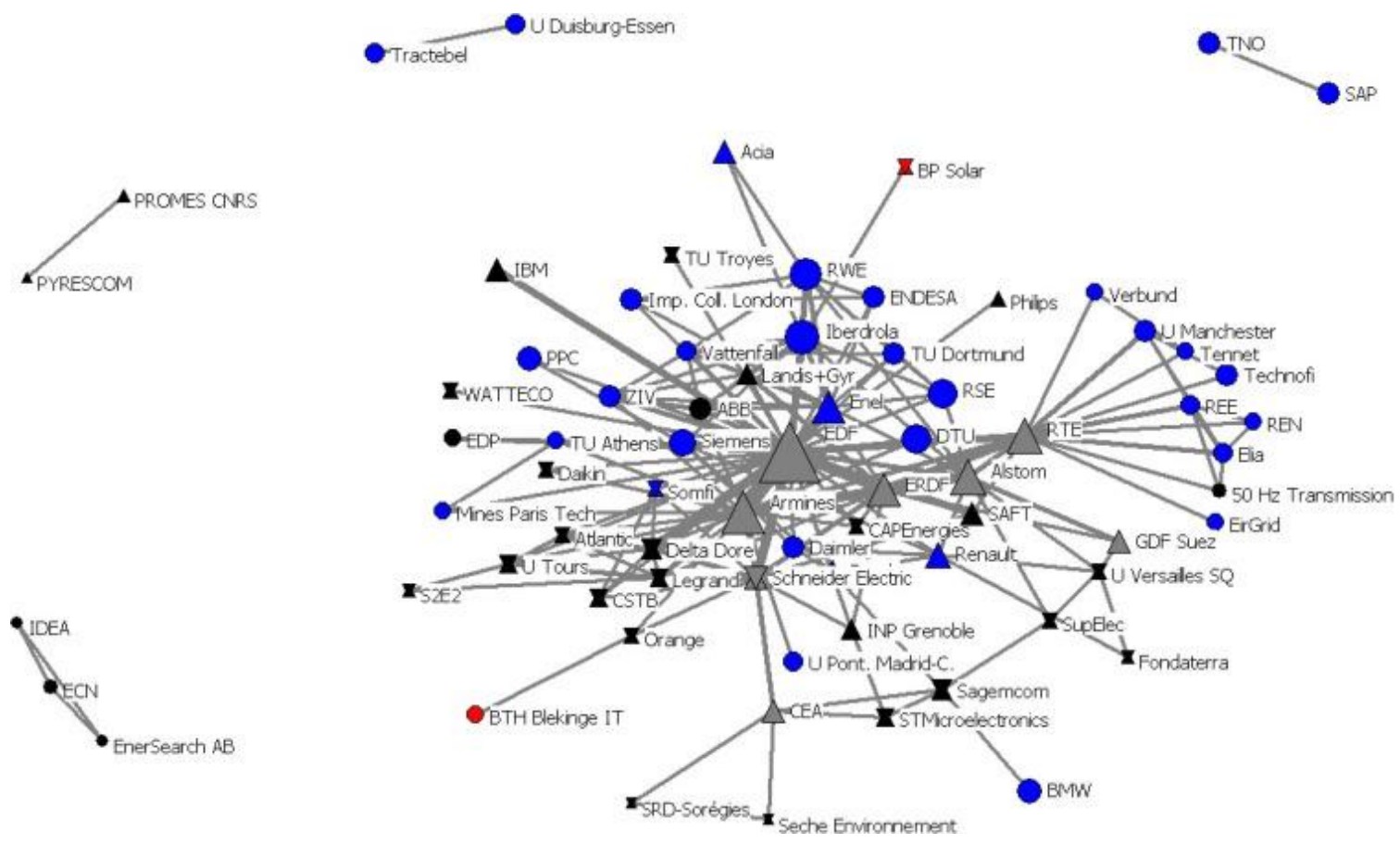

Graph 4. Network typology of French intense partnerships.

Caption: Scale (shapes): $\triangle$ France/ $\triangle$ France \& Europe/ Europe.

Typology (colors): $\square$ Experimenters/ Local observers/ Global observers/ Central actors

Note 1: Only partnerships with 2 cooperation links or more are represented here.

${ }^{8}$ European Union: Grid4EU with 25 partners and Green eMotion with 42 partners; ADEME: Smart Electric Lyon with 18 partners, Venteea with 10 partners, NiceGrid with 13 partners, Postes Intelligents with 3 partners, Smart Grid Vendée with8 partners,
Premio with 15 partners, GreenLys with 5 partners and Millener with 6 partners; Oséo: Homes with 13 partners; FUI: EcoLink with 12 partners and Enerstock with 7 partners. 
Note 2: TU stands for "Technological University" and U for "University". (For interpretation of the references to colour in this figure legend, the reader is referred to the web version of this article.)

Note 3: For interpretation of the references to colour in this figure legend, the reader is referred to the web version of th is article.

Table 6. Categorization of the 8 French central actors.

\begin{tabular}{ll}
\hline Actors & $\begin{array}{l}\text { Typology of organization (literature cate- } \\
\text { gorization) }\end{array}$ \\
\hline Alstom & $\begin{array}{l}\text { Supplier of transmission and distribution } \\
\text { infrastructure (2) }\end{array}$ \\
EDF & Energy supplier (1) \\
ERDF & Distribution system operator (1) \\
GDF Suez & Energy supplier (1) \\
RTE & Transmission system operator (1) \\
Schneider & Supplier of transmission and distribution \\
electric & infrastructure (2) \\
Armines & University/research center (3) \\
CEA & University/research center (3)
\end{tabular}

As previously performed, we categorized central actors according to the actors' typology found in the literature (see Table 6).

Once again, central actors, as defined by the network typology, come mostly from the energy sector (excepting research institutes).Furthermore, the homogeneity of French central actors is higher than worldwide because no ICT firm belongs to the central actors category, whereas, as previously stated, they are too numerous to become involved in the smart grid sector [19].

\subsection{Actors' strategies}

Using French actors' interviews, this section aims at highlighting the perceptions of the smart grid sector and, of course, its uncertainty, hiding behind the observed network positioning strategies identified with the network analysis.

\subsubsection{Energy sector and demand-oriented market}

In France, actors differentiate two smart grid secondary markets, one that is supply-oriented and the other, demand-oriented. The first one addresses updating and management of the grid's infrastructures. It is governed by well-established energy companies, most of them being part of the list of the French central actors. Furthermore, the previous network analysis has shown that the 8 and $15 \%$ of active actors (respectively worldwide and at French scale), i.e., experimenters and central actors, come from the energy sector.

The energy sector domination is noted by French actors as being the reason for the high degree of uncertainty characterizing the smart grid sector. Indeed, energy actors naturally follow a supply-oriented logic:

"What is changing is that now supply is limited because of the technical constraints of production and grids. However, we [energy suppliers] are still under the logic where supply tries to adapt demand to what we can offer and not the other way around...." \#6

As this supply-oriented market requires huge investments, new entrants are rare and can only be direct foreign competitors, i.e., from the energy sector.

Actors from the energy sector thus are not traditionally demand-oriented, even if they are currently modifying their approach. The prevalence of supplyoriented logic is, according to French actors, a real problem for smart grid viability. Indeed, the two secondary markets are supposed to balance one another to compensate for the smart grid cost/benefit analysis gap. To be more precise, the increasing investment costs in the supply-oriented market should be compensated for by the value created in the demand-oriented market. Hence, the emergence of a global and steady business model for smart grid mostly depends on the ability of smart grid actors to evolve from a supply-oriented to a demand-oriented market. However, as previously demonstrated in academics, in the smart grid sector the "incumbents of the focal sector", i.e., energy, have low transformation capacity [19].

This is a great concern, especially as the demandoriented secondary market, which mainly addresses demand response management, has not yet clearly identified its clients. Indeed, as stated in the literature review, end users, until now, have not been very interested in smart grid projects, despite attempts to create incentives, mainly using dynamic tariffs [22]. As it remains difficult to identify value sources, no business model has emerged:

"Concerning demand-response management, no business model currently exists." \#21

The positive way of considering the lack of smart grid demand is that, so far, everything still needs to be created. 


\subsubsection{Uncertainty or potentiality}

In an environment dominated by energy actors and their supply-oriented logic, it is difficult to change distribution on the smart grid value chain so that it may be beneficial to end users, at least partially. Consequently, some actors from other sectors are trying to enlarge the smart grid's perimeter, beyond energy, to stimulate demand and depart from the supply-oriented logic:

"According to me, smart grid is an optimization system of the consumption of a fluid resource, whatever it is." \#18"

For now, [smart grid] uses mostly electricity, but the grid is evolving more and more towards gas and heating grids or evenwater." \#33

"Beyond the electrical grid is the Smart Home and even the Smart City. We are working, for example, on dashboards to allow local authorities to monitor and control many uses far beyond energy: transportation, waste, water, electrical vehicle, health, the elderly, etc." \#29

Based on this enlarged vision of smart grid, some French actors (and others abroad, see, for example, Ref. $[1,2,4])$ are currently testing end users' services, combining energy management with safety devices, air quality monitoring or home care for the elderly. From these actors' point of view, which is generally unfamiliar to the energy sector, smart grid is indeed a very attractive market mainly because it has suddenly emerged, carrying new potential expectations. For firms settled in nearly saturated markets (for example, ICT), smart grid offers a credible alternative to ensure their growth and technical development. From this perspective, they want to be ready to jump into the market if ever it reveals its potential:

"Everyone is waiting and everyone is cautious, but everyone is curious to see what will happen. It is a little like a street show, people are joining just to have a look. They are doing nothing, but they are not totally in a 'wait and see' posture. [...] However, people interested in business models are wondering: "what new actors will emerge? What markets will emerge? Do I have a space? When should I invest?" And it is like in a chess game: pragmatic vision, but unclear. Each and every one, we are all looking for a vision of potential markets. And there is no altarboy." \#37
Even, some French actors argue that smart grid could be a type of market bubble, having doubts about its short-term viability:

"These Ciscos, IBMs and others implemented huge projects. And they communicated a lot on them. And now the soufflè is collapsing." \#28"

I sincerely think that there is a kind of market bubble. One talks a lot about smart grid. . . at the beginning, our 100 partners imagined important market shares and a huge volume of business. However, they will be disappointed as they get a fifth or so..." \#14

If pragmatism allows new ideas, the unclear definition and perimeter of smart grid induces uncertainty about the possible emergence of demand, which feeds actors' caution, enclosing the smart grid sector into a vicious circle that is very difficult to break.

This cautious positioning is also visible through the network analysis. Indeed, among the four types of actors, two of them-local and global observersreflect the "wait and see" position. What is surprising here is that these observers account for $92 \%$ of the worldwide smart grid actors and $85 \%$ of the French actors. In accordance with previous analyses, these numerous observers, most of whom are established actors from another sector, should be more likely than central actors from the energy sector to transform the smart grid sector [19, 35].

However, so far, the transformative capacity of smart grid attributed to observers coming from other sectors has not emerged because this means offering a convincing vision, which does not exist yet. It also means commitment in local institutional structures and networks $[28,49]$. Thus, the strongly structured cautious positioning observed in this paper is handicapping the smart grid development, as it reveals the absence of willingness of observers from other sectors to invest massive resources in such networks.

National administrations and politicians, whether aware or unaware of this reality, can play a crucial part here. Through projects funded in whole or in part by public money, a common and shared vision of smart grid could finally emerge. Indeed, these projects allowed for the creation of cooperation routines between regular partners, visible in the secondary cooperation networks. The possibility of experimenting with technical solutions together is 
indeed a way to create convergence between different visions of the sector:

"Technically speaking, huge converging work has been launched for a few years with demonstration projects." \#17

"Demonstration projects funded through the IA ["Investissement d'avenir", i.e., specific French funding] are, from what l've been told, precisely aiming at assessing the cake's size and the share each can get. Some partners really want to build a converging vision of the smart grid market to promote it among public authorities." \#21

Hence, the issue of the viability of business model for the smart grid market could be solved by promoting a common vision of smart grid shared by the actors among public authorities. As the smart grid value seems to be nested at the crossroads of several secondary markets, French public authorities can be helpful to ease and, when necessary, to regulate discussions between competing actors.

\subsubsection{Embedded strategies}

The schematic distinction previously stated between observers and active actors has to be qualified. Indeed, superposed dynamics are visible in the smart grid socio-technical system. For instance, we demonstrated that central actors were simultaneously implementing monitoring and experimentation strategies, i.e., a cumulative strategy. Furthermore, comparison between the worldwide and the French scale makes the various strategies implemented by a single actor visible. For example, an actor seen as central worldwide, such as Siemens, becomes a global observer when considered on a smaller scale. It is thus empirically visible that actors have multilevel strategies, reinforcing the interest in studying the interactions between the actors' microlevel and the socio-technical system's mesolevel. Sometimes these strategies are cumulative (having several strategies at the same time), and sometimes they are differentiated (a strategy for a territory, another one elsewhere).

Empirical data reveal three levels of cooperation in accordance with insights from innovation studies on cooperation strategies $[11,32,58]$. First, relationships that are often exclusive have developed on an intra-company basis in a high-risk context regarding investment. In this case, enterprises chose joint venture or strategic alliances to share technology and even product creation. At this first level, considering smart grid relationships, we find cooperation between EDF and Veolia Environment through Dalkia or more recently Bouygues and Alstom through Embix (joint-venture dedicated to smart grid). Indeed, there is a de facto relational ecosystem associated with R\&D projects as described by actors:

"We built an ecosystem with clients, technological partners who complete our offer, but also partners who allow us to test, in other adjacent domains, our technical solution currently implemented on electrical grid. For example, energy management in buildings, done with $X$ : it is a partner; energy management in electric vehicles done with Y: it is a partner; and so on. [...] We are trying to propose integrated solutions to client. The ecosystem really eases project development. [...] On smart grid, itis not optimal to work 'in silos' [in isolation], i.e., having all competences. It is better to interface with others." \#31

Second, actors also develop relationships at intercompany levels to coordinate several technologies. As previously observed in the cooperation network analysis, actors have built portfolios of partners (consortia, standardization lobby, etc.) to achieve technical agreements or standards:

"We have a predefined architecture; we have standards we would like to reuse. That is why we took part in R\&D projects and also in standardization committees at the European and US levels, to promote these standards and to reuse them in our projects. Hence, [we have] always three principles: architecture and standards, and then an ecosystem." \#32

Third, coordination can be implemented at the extra-company level to influence commercial environments and regulatory organizations through shared or converging political positions. In France, the "smart grids France" initiative embodies this multilevel embedding of strategies. Indeed, it gathers 9 competitive clusters (inter-company level) to frame a shared vision between members to influence sectorial evolution (extra-company level) and further cooperation in projects (intra-company level):

\footnotetext{
"'Smart grids France' aims at raising awareness among enterprises and demonstration projects to standard-use cases. For example, if something has already been done elsewhere, can we reuse it and so on. The interest here is for industrials. It is important that industrialists should, in
} 
the end, be able to value this converging position. It shapes the chain value. And technologically speaking, it is about lifting together some levers to spread technologies everyone can use." \#27

However, competition is still real between actors. Indeed, field-work has taught us how difficult it remains to access projects results, even when funded by public money. Indeed, in a moving and uncertain context, actors find it difficult to identify which piece of information is crucial or not to be competitive in an emerging market. We are faced with significant reluctance by actors to communicate on smart grid, mostly about R\&D projects' difficulties, lessons and results:

“Elements for business models and R\&D projects have to remain confidential in the company. Indeed, we know they are false. If not, we would not need to develop a project to test them. They are more like hypotheses for provisional business cases. And they evolve with the project's results and then influence internal predictions.

We will not talk about that." \#3

Indeed, based on the original research project hosted in this study, we planned to study French case studies of demonstration projects. However, we did not manage to access data or results or even the technical information submitted to public funding agencies. We found that data access on strategic positioning or project content is strongly limited and sometimes forbidden. Thus, the case studies were abandoned. There are probably multiple reasons for this, but after our fieldwork, two options appeared. First, the fact of not communicating on projects is a way to limit newcomers' ability to learn about the smart grid sector and is thus a way to restrict possible competition. The purpose is to protect existing knowledge and dominating positions. Second, not communicating on projects is away to hide the fact that no tangible results have emerged. However, this restricted communication strategy is a real brake, once again, on the emergence of a shared and robust vision of smart grid and on the decrease of uncertainty regarding the sector $[1,5]$.

\section{Conclusions}

This article argues that, whereas it is necessary to limit uncertainty and thus secure the sector's development and durability in the coming years, no structuring and shared vision of smart grid has emerged among stakeholders. It empirically demonstrates that the cooperation network between smart grid actors reflects the progress of the emergence of such a shared vision, which is the very first step to reducing uncertainty.

Based on an original methodology that combines qualitative and quantitative approaches, we first provide an overview of the worldwide cooperation network of smart grid actors. The social network analysis shows that actors are weakly related, meaning that the sector is not highly integrated in terms of cooperation strategies. It also allows us to identify four categories of actors regarding cooperation strategies: local observers (onlookers in a few local projects), global observers (onlookers in a few international projects), local experimenters (active participants in several local projects with experimental aspects), and central actors (multilevel actors actively involved in numerous projects with experimental aspects, both at local and international levels). This analytical typology highlights that worldwide smart grid is organized around a few active actors-experimenters and central actors are $7.7 \%$ of the worldwide stock smart grid actorswhich are observed by a huge amount of passive ones-local and global observers are the remaining $92.3 \%$ of actors.

Second, we show that the analytical distinction between the four categories deduced from the network analysis reveals positioning strategies, each associated to one specific category of actors. On the one hand, experimenters and especially central actors appeared to be long-established actors in the field of energy. The analysis of semi-structured interviews with French actors indicates that energy actors are promoting a very accurate vision, but it is strictly energy-oriented for the sector, i.e., supplyoriented. On the other hand, global and local observers are mostly new entrants, recently born or coming from connected sectors. In interviews, they are depicted as offering a demand-oriented approach. Thus, they seem to be open to many options for further developments, but until now they have only given an indistinct definition of what smart grid could be. Therefore, actors diverge on the definition, perimeter and potential source of added value in smart grid. Furthermore, the actors' discourse oscillates between enthusiasm, leaning against a voluntary positioning strategy, and reluctance regarding reality and potentialities of smart grid embodied by a cautious positioning. 
However, these two "active" and "passive" strategies can be implemented at the same time: in a highly uncertain context, taking a resolute position prevents competitors from winning market shares, whereas a cautious strategy prevents them from risking massive investments. During our fieldwork, we also experienced that, in this context of toughened competition, smart grid actors are-at least in France-very reluctant to share results and ideas. Hence, they are unable to build a shared and structured vision of smart grid that they could promote to public authorities to influence orientations concerning $R \& D$ funding, regulation or economic policies. By doing so, they would be able to reduce uncertainty in the sector, thus allowing potential prospective achievements.

From a theoretical point of view, these results based on the smart grid sector analysis allow us to propose new insights on the transition of socio-technical systems. Indeed, the situation observed in this case through networking cooperation strategies questions the validity of analyses showing that the actors' potential for transition enhancement would be higher in connected sectors than in the focal sector $[19,35]$. At this very moment where contextual uncertainty remains high, it appears that active actors-here, coming from the focal sector of energy-play a crucial part in driving the current sector development, whereas new entrants-mainly from the connected ICT sector-remain unable to decisively modify the smart grid sector's regime. It appears that success of the evolution of socio-technical system depends not only on actors' sectoral typology or origin $[19,27,35]$ but also on cooperation strategy, which is perceived as a powerful tool to foster the emergence of a shared vision among actors [5]. One can interpret this situation as a sign for the failure of the smart grid sector to emerge as such. On the other hand, one can see here a strategic evolution of actors from the focal sector regarding uncertainty in an innovative socio-technical system in transition. To solve this issue, further studies should be conducted both on the smart grid sector to see how it will evolve and on other sectors to search for potential similar trends.

\section{Acknowledgments}

The author would like to thank the anonymous reviewers for their valuable comments and suggestions to improve the paper. This research work has been performed within the BRASIL project (BRASIL stands for Bâtiments et Réseau d'énergie: Anticipation des Services Intelligents, i.e., Building and Energy Grids: Anticipating Smart Services), funded by ADEME (French Agency for Environment and Energy Control) and CSTB (French Center for Building Research) through the ADEME Convention No. $1210 \mathrm{C0005}$, notified on 08/06/12, and implemented in cooperation with Sylvain Laurenceau (CSTB) on economic aspects. A detailed version of the results presented here is available in French [57].

\section{References}

[1] S. Bakker, H. Van Lente, M. Meeus, Arenas of expectations for hydrogen technologies, Technol. Forecast. Soc. Change 78 (January (1)) (2011) 152162.

[2] J.C.J.M. Van den Bergh, B. Truffer, G. Kallis, Environmental innovation and societal transitions: introduction and overview, Environ. Innov. Soc. Transit. 1(June (1)) (2011) 1-23.

[3] J.W. Black, Demand Response as a Substitute for Electric Power System Infrastructure Investments, MIT, 2005.

[4] S. Blumsack, A. Fernandez, Ready or not, here comes the smart grid!, Energy37 (January (1)) (2012) 61-68.

[5] M. Borup, N. Brown, K. Konrad, H. Van Lente, The sociology of expectations in science and technology, Technol. Anal. Strateg. Manage. 18 (July (3-4)) (2006)285-298.

[6] C. Brancucci Martínez-Anido, R. Bolado, L. De Vries, G. Fulli, M. Vandenbergh,M. Masera, European power grid reliability indicators, what do they really tell? Electr. Power Syst. Res. 90 (September) (2012) 79-84.

[7] H.E. Brown, S. Suryanarayanan, G.T. Heydt, Some characteristics of emerging distribution systems considering the smart grid initiative, Electr. J. 23 (4)(2010) 64-75.

[8] R.E. Brown, Impact of Smart Grid on distribution system design, IEEE (July)(2008) 1-4.

[9] M. Callon, Civilizing markets: Carbon trading between in vitro and in vivo experiments, Accounting, Organizations and Society 34 (3-4) (2009) 535548,2009 .

[10] M. Callon, What Does It Mean to Say That Economics is Performative? Do Economists Make 
Markets? On the Performativity of Economics, Princeton Press, 2007, pp. 311-357.

[11] Y. Caloghirou, S. Ioannides, N.S. Vonortas, Research joint ventures, J. Econ.Surv. 17 (September (4)) (2003) 541-570.

[12] C. Clastres, Smart grids: another step towards competition, energy security and climate change objectives, Energy Policy 39 (9) (2011) 5399-5408.

[13] D. Coll-Mayor, M. Paget, E. Lightner, Future intelligent power grids: analysis of the vision in the European Union and the United States, Energy Policy 35(4) (2007) 2453-2465.

[14] H.C. Curtius, K. Künzel, M. Loock, Generic customer segments and business models for smart grids: empirical evidence from a cross-European country study, Der Markt 51 (2-3 August) (2012) 63-74.

[15] R. Davis, J. Hartford, Demand-Side Bidding in a Competitive Electricity Market, EATechnology, 2004.

[16] G. Dokko, A. Nigam, L. Rosenkopf, Keeping steady as she goes: a negotiated order perspective on technological evolution, Organ. Stud. 33 (June (5-6)) (2012) 681-703.

[17] U. Dolata, Technological innovations and sectoral change, Res. Policy 38 (July (6)) (2009) 10661076.

[18] EPRI, Estimating the Costs and Benefits of the Smart Grid: A Preliminary Estimate of the Investment Requirements and the Resultant Benefits of a Fully Functioning Smart Grid, EPRI, 2011.

[19] S. Erlinghagen, J. Markard, Smart grids and the transformation of the electricity sector: ICT firms as potential catalysts for sectoral change, Energy Policy 51 (December) (2012) 895-906.

[20] European Parliament and Council of the European Union, 2009. Directive2009/72/EC of the European Parliament and of the Council of 13 July 2009concerning common rules for the internal market in electricity and repealingDirective 2003/54/EC. Off. J. Eur. Union. 14.8.2009 (July 2009), 55-93.

[21] $\mathrm{H}$. Farhangi, The path of the smart grid, IEEE Power Energy Mag. 8 (January (1)) (2010) 18-28.

[22] A. Faruqui, D. Harris, R. Hledik, Unlocking the [euro] 53 billion savings from smart meters in the EU: how increasing the adoption of dynamic tariffs could make or break the EU's smart grid investment, Energy Policy 38 (10) (2010)6222-6231.

[23] P.S. Fox-Penner, Smart Power: Climate Change, the Smart Grid, and the Future of Electric Utilities, Island Press, 2010.

[24] L.C. Freeman, Centrality in social networks. Conceptial clarification, Soc.Netw. 1 (1979) 215239.

[25] F. Gangale, A. Mengolini, I. Onyeji, Consumer engagement: an insight from smart grid projects in Europe, Energy Policy 60 (September) (2013) 621628.

[26] F.W. Geels, From sectoral systems of innovation to socio-technical systems, Res. Policy 33 (September (6-7)) (2004) 897-920.

[27] F.W. Geels, R. Kemp, Dynamics in socio-technical systems: typology of change processes and contrasting case studies, Technol. Soc. 29 (November (4))(2007) 441-455.

[28] F.W. Geels, J. Schot, Typology of sociotechnical transition pathways, Res.Policy 36 (April (3)) (2007) 399-417.

[29] P. Geoffron, M. Guichoux, Economie des smart grids: focus sur l'expérienceallemande 2011.

[30] V. Giordano, G. Fulli, A business case for smart grid technologies: a systemic perspective, Energy Policy 40 (November) (2011) 252-259.

[31] S. Hall, T.J. Foxon, Values in the smart grid: the co-evolving political economy of smart distribution, Energy Policy 74 (November) (2014) 600-609.

[32] R. Hawkins, R. Mansell, J. Skea, Standards, Innovation and Competitiveness: The Politics and Economics of Standards in Natural and Technical Environments, Edward Elgar, 1995.

[33] W.W. Hogan, Demand response compensation, net benefits and costal location: comments, Electr. J. 23 (2010) 19-24.

[34] Joint Research Centre, Smart Grids Projects in Europe: Lessons Learned and Current Developments-Update 2012, European Commission (JRC \& Institute for Energy and Transport), 2013.

[35] S. Kaplan, M. Tripsas, Thinking about technology: applying a cognitive lens to technical change, Res. Policy 37 (June (5)) (2008) 790-805.

[36] C. Koliba, M. DeMenno, N. Brune, A. Zia, The salience and complexity of building, regulating, and 
governing the smart grid: lessons from a statewide public-private partnership, Energy Policy 74 (November) (2014) 243-252.

[37] H. van Lente, Promising Technology: The Dynamics of Expectations in Technological Developments, Eburon Publ., 1993.

[38] C.-C. Lin, C.-H. Yang, J.Z. Shyua, A comparison of innovation policy in the smart grid industry across the pacific: China and the USA, Energy Policy 57(June) (2013) 119-132.

[39] S. Luthra, S. Kumar, R. Kharb, M.F. Ansari, S.L. Shimmi, Adoption of smart grid technologies: an analysis of interactions among barriers, Renew. Sustain.Energy Rev. 33 (May) (2014) 554-565.

[40] D. MacKenzie, Y. Millo, Constructing a market, performing theory: the historical sociology of a financial derivatives exchange, Am. J. Sociol. 109 (1)(2003) 107-145.

[41] D.N. Mah, J.M. van der Vleuten, J. Chi-man Ip, P. Ronald Hills, Governing the transition of sociotechnical systems: a case study of the development of smart grids in Korea, Energy Policy 45 (June) (2012) 133-141.

[42] D.N. Mah, J.M. van der Vleuten, P. Hills, J. Tao, Consumer perceptions of smart grid development: results of a Hong Kong survey and policy implications, Energy Policy 49 (October) (2012) 204-216.

[43] D.N. Mah, Y.-Y. Wu, J.C. Ip, P.R. Hills, The role of the state in sustainable energy transitions: a case study of large smart grid demonstration projects in Japan, Energy Policy 63 (December) (2013) 726737.

[44] F. Malerba, Sectoral systems of innovation and production, Res. Policy 31(February (2)) (2002) 247264.

[45] R.O. Van Merkerk, D.K.R. Robinson, Characterizing the emergence of a technological field: expectations, agendas and networks in lab-on-a-chip technologies, Technol. Anal. Strateg. Manage. 18 (July (3-4)) (2006) 411-428.

[46] A. Molina-Markham, G. Danezis, K. Fu, P. Shenoy, D. Irwin, Designing privacy-preserving smart meters with low-cost microcontrollers, in: A.D.Keromytis (Ed.), Financial Cryptography and Data Security, Springer, Berlin, Heidelberg, 2012, pp. 239-253.

[47] S. Muench, S. Thuss, E. Guenther, What hampers energy system transformations? The case of smart grids, Energy Policy 73 (October) (2014)8092.

[48] N. Murtagh, B. Gatersleben, D. Uzzell, A qualitative study of perspectives on household and societal impacts of demand response, Technol. Anal. Strateg.Manage. 26 (November (10)) (2014) 11311143.

[49] J. Musiolik, J. Markard, M. Hekkert, Networks and network resources in technological innovation systems: towards a conceptual framework for system building, Technol. Forecast. Soc. Change 79 (July (6)) (2012)1032-1048.

[50] F. Picard, K. Cabaret, Politique européenne de l'énergie et transition vers un système énergétique décarboné fondée sur les Smart Grids, Innovations 46(1) (2015) 33.

[51] M. Pipattanasomporn, H. Feroze, S. Rahman, Multi-agent systems in a distributed smart grid: design and implementation. (March) (2009), 1-8.

[52] M. Pullinger, H. Lovell, J. Webb, Influencing household energy practices: acritical review of UK smart metering standards and commercial feedback devices, Techno. Anal. Strateg. Manage. 26 (November (10)) (2014)1144-1162.

[53] L. Lo Schiavo, M. Delfanti, E. Fumagalli, V. Olivieri, Changing the regulation for regulating the change: innovation-driven regulatory developments for smart grids, smart metering and e-mobility in Italy, Energy Policy 57 (June) (2013)506-517.

[54] Smart Grid. Integrating Renewable, Distributed \& Efficient Energy, in: F.P. Sioshansi (Ed.), Academic Press, 2011.

[55] T.M. Skjølsvold, Back to the futures: retrospecting the prospects of smart grid technology, Futures 63 (November) (2014) 26-36.

[56] A. Tricoire, Energy Savings in Social Housing: How to Involved the Tenants? (2010).

[57] A. Tricoire, S. Laurenceau, BRASIL: Analyse transversale du secteur du smartgrid. Rapport intermédiaire. Technical Report \#ER-873-122001-873IMM.ADEME \& CSTB, (2013).

[58] T. Van der Valk, M.M.H. Chappin, G.W. Gijsbers, Evaluating innovation networks in emerging technologies, Technol. Forecast. Soc. Change 78(January (1)) (2011) 25-39.

[59] G. Verbong, F. Geels, The ongoing energy transition: lessons from a socio-technical, multi-level 
analysis of the Dutch electricity system (19602004), Energy Policy 35 (February (2)) (2007) 10251037.

[60] G.P.J. Verbong, S. Beemsterboer, F. Sengers, Smart grids or smart users? Involving users in developing a low carbon electricity economy, Energy Policy52 (January) (2013) 117-125.

[61] M. Wissner, ICT, growth and productivity in the German energy sector-Ont he way to a smart grid? Util. Policy 19 (January (1)) (2011) 14-19.

[62] World Economic Forum, Accelerating Successful Smart Grid Pilots, World Economic Forum, 2010.

[63] D. Xenias, C. Axon, N. Balta-Ozkan, L. Cipcigan, P. Connor, R. Davidson, A.Spence, G. Taylor, L. Withmarsh, Scenarios for the Development of Smart Grids in the UK: Literature Review, UK Energy Research Centre, 2014. 